\title{
Matched development of a pair of monozygous twins of grossly different size at birth
}

\author{
J. M. H. BUCKLER and A. ROBINSON* \\ From the Children's Department, St. Bartholomew's Hospital, London
}

\begin{abstract}
Buckler, J. M. H., and Robinson, A. (1974). Archives of Disease in Childhood, 49, 472. Matched development of a pair of monozygous twins of grossly different size at birth. Monozygous twins had birthweights differing by $1.64 \mathrm{~kg}$. The smaller twin, only $45 \%$ of her sister's weight, rapidly caught up, and at the age of 10 years physical growth was similar and there was negligible difference in their intelligence and educational attainment.
\end{abstract}

Inadequate nutrition of the fetus in the last trimester of pregnancy frequently has long lasting sequelae manifest by a retardation of physical growth and mental development. This is well illustrated by studies of monozygous twins with greatly differing birthweights. This report describes an extreme example of such twins in which, however, the smaller twin did not prove subsequently to be in any way inferior developmentally.

\section{Case report}

On 21 May 1963, twin girls were born, the pregnancy having been complicated by an antepartum haemorrhage for $1 \frac{1}{2}$ days at the 18 th week which settled spontaneously. At 38 weeks the mother developed mild toxaemia and was admitted to hospital a week later. The fundal height at that stage corresponded to a 38-week pregnancy. Labour was induced by artificial rupture of the membranes and 4 hours later the first baby was delivered. Intramuscular ergometrine had been given at the crowning of the head. 15 minutes later, the undiagnosed second twin was born.

The appearance of the twins shortly after birth is shown in Fig. 1(a). The first twin (A) weighed $2.99 \mathrm{~kg}$ and her condition was satisfactory. She appeared normal and mature. The second twin (B) weighed 1.35 $\mathrm{kg}$ and was limp and pale at birth, but rapidly improved. She showed features of 'dysmaturity' being very thin, with wrinkled skin and marked lack of subcutaneous fat, but was otherwise normal. Measurements of the twins at birth are shown in Table I.

Investigations in the neonatal period showed a mild degree of anaemia in the smaller twin $\mathrm{B}(\mathrm{Hb} 16.6 \mathrm{~g} / 100$ $\mathrm{ml}$ ) compared with twin A (Hb 22.4 g/100 ml). Twin $A$, however, became mildly jaundiced with a serum

Received 21 November 1973.

^Present address: Royal West Sussex Hospital, Chichester.
TABLE I

Measurements at birth

\begin{tabular}{l|c|c}
\hline & Twin A & Twin B \\
\hline Weight $(\mathrm{kg})$ & $2 \cdot 99$ & $1 \cdot 35$ \\
Length $(\mathrm{cm})$ & 50 & 42 \\
Head circumference (cm) & $32 \cdot 5$ & 30 \\
Chest circumference (cm) & 32 & 24 \\
& & \\
\hline
\end{tabular}

bilirubin of $9.5 \mathrm{mg} / 100 \mathrm{ml}$ on day 3, whereas the level in twin B never exceeded $2.0 \mathrm{mg} / 100 \mathrm{ml}$. $X$-rays of the knees showed lower femoral epiphyses present in twin A but absent in twin B. Ossific centres for talus and calcaneum were present in both twins but were smaller in twin B. Most of the other investigations were, however, normal and similar in the twins, i.e. blood sugar, blood urea, plasma electrolytes, plasma proteins, and electrophoresis, and levels of fetal $\mathrm{Hb}$. Blood groups including full subgrouping were identical, and are shown together with those of the parents in Table II.

Placenta. The placenta was diamniotic-monochorionic and weighed $825 \mathrm{~g}$. It was separable into two

TABLE II

Blood groups of twins and their parents

\begin{tabular}{l|l|l|l|l}
\hline \multicolumn{1}{c|}{ Blood group } & Twin A & Twin B & Mother & Father \\
\cline { 2 - 3 } ABO & O & O & O & A \\
Rh phenotype & CcDee & CcDee & CcDee & CcDee \\
Probable genotype & CDe/cde & CDe/cde & CDe/cde & CDe/cde \\
MN & MN & MN & NN & MN \\
S & - & - & - & - \\
Pl $_{1}$ & - & - & + & - \\
$\mathbf{L u}^{\mathbf{a}}$ & - & - & - & - \\
Ky $_{\text {Fy }}$ & - & - & - & - \\
& + & + & + & + \\
\hline
\end{tabular}




\section{Matched development of a pair of monozygous twins of grossly different size at birth}

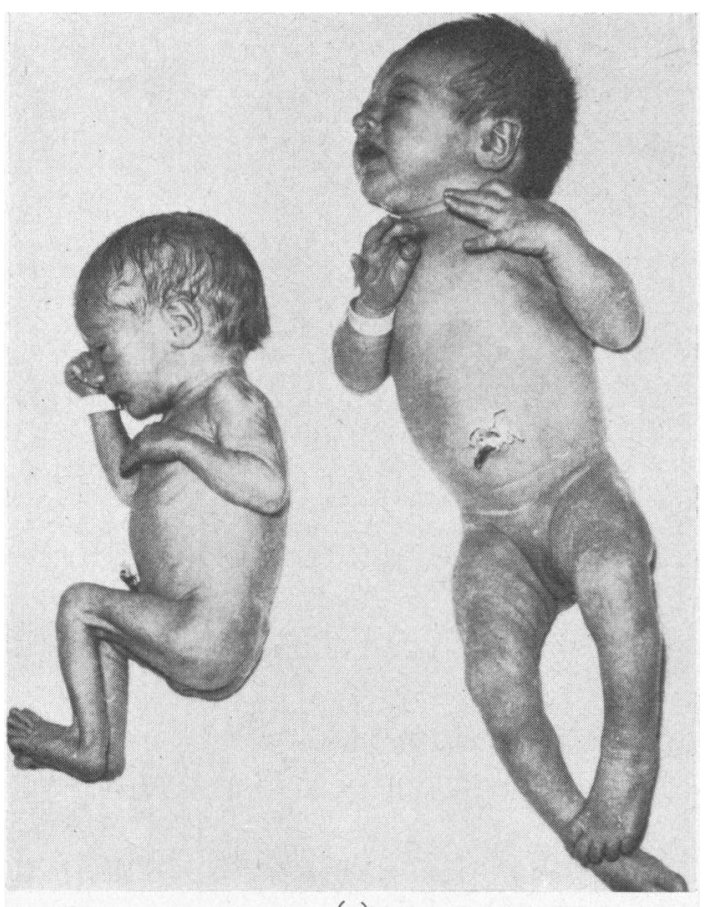

(a)

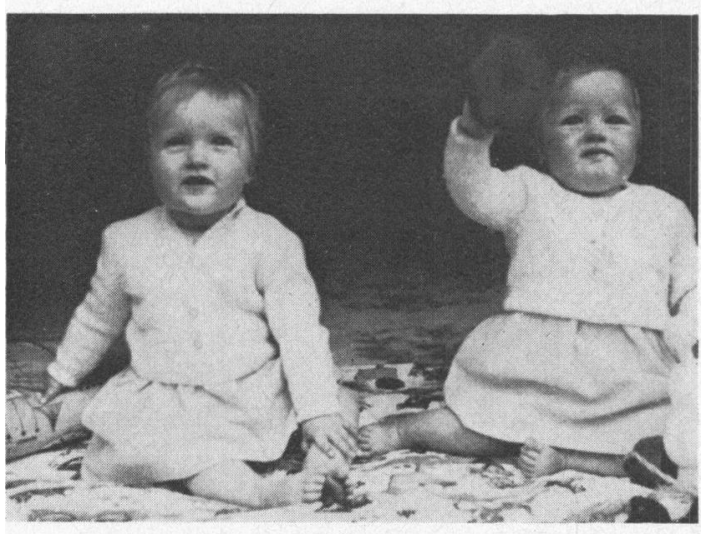

(b)

FIG. 1.-Appearance of the twins (a) shortly after birth and (b) at 11 months. Twin $B$ is on the left.

parts weighing $440 \mathrm{~g}$ and $385 \mathrm{~g}$ which were connected respectively with the cords, both normal in appearance, of the larger and smaller twins. The two halves of the placenta were of approximately the same surface area, but the heavier half was paler and thicker, and much better vascularized. There was no macroscopical infarction or calcification. The anatomy and vascular supply of the placenta is illustrated in Fig. 2, which shows the anastomotic communications between the two halves and a shared cotyledon.

On histology, the larger, healthier appearing half of the placenta showed normal chorionic villi and vessels, with minimal infarction. The smaller half, though normal in appearance in some areas, showed in others small, densely crowded chorionic villi with narrow vessels and extensive infarction.

Initial progress. Both twins thrived satisfactorily. Twin A was breast fed for 10 days, then bottle fed. Her weight fell by $210 \mathrm{~g}$ to $2 \cdot 78 \mathrm{~kg}$ and she did not regain her birthweight for 17 days. In contrast, twin B, who remained in an incubator for 4 days and in hospital for 5 weeks, never lost any weight. She had no feeding problems and by 17 days her weight had reached $1.73 \mathrm{~kg}$. She was fed for one week on expressed breast milk but then changed to the same bottle feed as her sister. She became sufficiently anaemic at 5 weeks to require a small blood transfusion when $\mathrm{Hb}$ had fallen to $8 \cdot 3 \mathrm{~g} / 100 \mathrm{ml}$. Twin A did not develop significant anaemia and her $\mathrm{Hb}$ never fell below $11 \mathrm{~g} / 100 \mathrm{ml}$.

Over the course of the first year, the smaller twin caught up her larger sister rapidly. At 14 weeks the weights of twins $A$ and $B$ were 4.54 and $5.78 \mathrm{~kg}$, and at $11 \frac{1}{2}$ months $7 \cdot 63$ and $7.94 \mathrm{~kg}$, respectively. Skull circumferences at 14 weeks were $39.5 \mathrm{~cm}$ and $38 \mathrm{~cm}$, and chest circumferences $40 \mathrm{~cm}$ and $38 \mathrm{~cm}$ of twins $A$ and $B$, respectively.

Bone $x$-rays showed that lower femoral epiphyses, present in twin A at birth, had not appeared in twin B at 1 month but by 3 months had appeared together with upper tibial epiphyses, and on the basis of wrist $x$-rays there was little difference in the bone ages of the twins by this time.

The general appearance of the twins at the age of 11 months, when they had become almost indistinguishable, is shown in Fig. $1(b)$.

After a slight initial difference, the twins developed neurologically in a remarkably similar manner. In the newborn period neither baby behaved as a premature, and neurological testing in both was in keeping with full maturity. Twin A smiled at 7 weeks, a little earlier than twin B. She had sitting balance at 7 months, about 2 months ahead of her twin. However, from the age of 1 year development of the twins was similar, and both were standing holding on at 14 months and walking unaided at 16 months. Development of speech was similar and both were using sentences by 2 years. They were crawling up stairs at 18 months, dressing themselves by 3 years, were dry by day and no longer soiling shortly after 2 , and dry by night by 3 . First teeth appeared in both at 13 months. Gesell testing at 2 years showed both to have a development commensurate with their age.

The development of the twins had been as rapid as that of their 3 sibs. An elder sister, born in February 1962 weighing $3.40 \mathrm{~kg}$ at birth, walked at 13 months. A younger sister born in September 1965 had a birthweight of $2.98 \mathrm{~kg}$ and walked at 15 months. A brother weighing $3 \cdot 40 \mathrm{~kg}$ was born in April 1968 and walked at 19 months.

The twins have remained free from serious illness, but manifested a familial tendency to allergy. Twin A had eczema between the ages of 2 and 5 , and twin B showed 


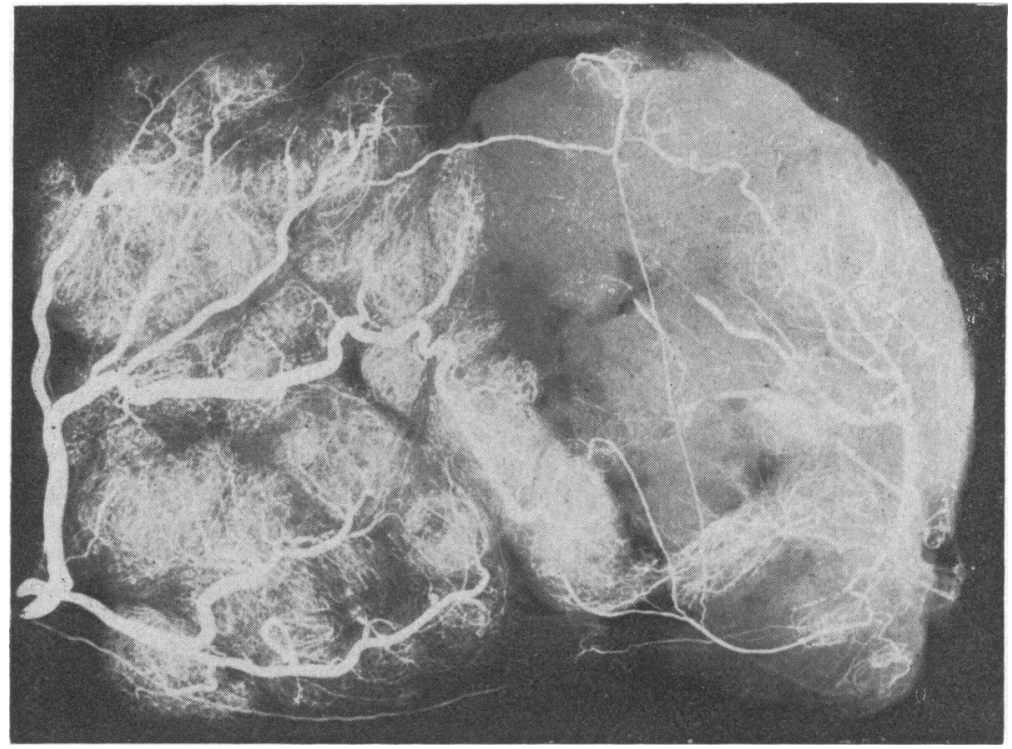

FIG. 2.-X-ray of placenta after injection of micropaque through the cord of the larger twin.

evidence of asthmatic bronchitis with catarrhal symptoms and wheeziness at the age of 7 and had her tonsils removed at the age of $9 \frac{1}{2}$.

Recent assessment. The twins were re-examined in October 1973 at the age of 10 years 5 months. Their physical measurements are listed in Table III, and Fig. 3 is a photograph taken shortly before. Twin A was a healthy well-nourished child, with evidence of left cerebral dominance and no abnormality on physical examination.

The measurements of twin B were very similar apart from weight and head circumference. Though the heights were identical, twin A was slightly bigger in trunk measurements and twin $B$ in the length of her limbs.

TABLE III

Physical measurements at age 10 years 5 months

\begin{tabular}{l|c|c}
\hline & Twin A & Twin B \\
\hline Weight (kg) & $33 \cdot 7$ & $30 \cdot 4$ \\
& $(75-90$ th centile $)$ & $(50-75$ th centile) \\
& $145 \cdot 7$ & $145 \cdot 7$ \\
Height (cm) & $(75-90$ th centile) & $(75-90$ th centile) \\
Span (cm) & $146 \cdot 5$ & $147 \cdot 0$ \\
Head circumference (cm) & $52 \cdot 0$ & $51 \cdot 0$ \\
Chest circumference (cm) & $63 \cdot 5$ & $64 \cdot 0$ \\
Sitting height (cm) & $75 \cdot 7$ & $74 \cdot 8$ \\
Biacromial diameter (cm) & $33 \cdot 4$ & $33 \cdot 2$ \\
Bi-iliac diameter (cm) & $22 \cdot 2$ & $21 \cdot 7$ \\
Skinfolds (cm) & $0 \cdot 68$ & $0 \cdot 44$ \\
Biceps & $1 \cdot 08$ & $0 \cdot 90$ \\
Triceps & $0 \cdot 81$ & 0.54 \\
Subscapular & $0 \cdot 62$ & 0.43 \\
Suprailiac & & \\
& &
\end{tabular}

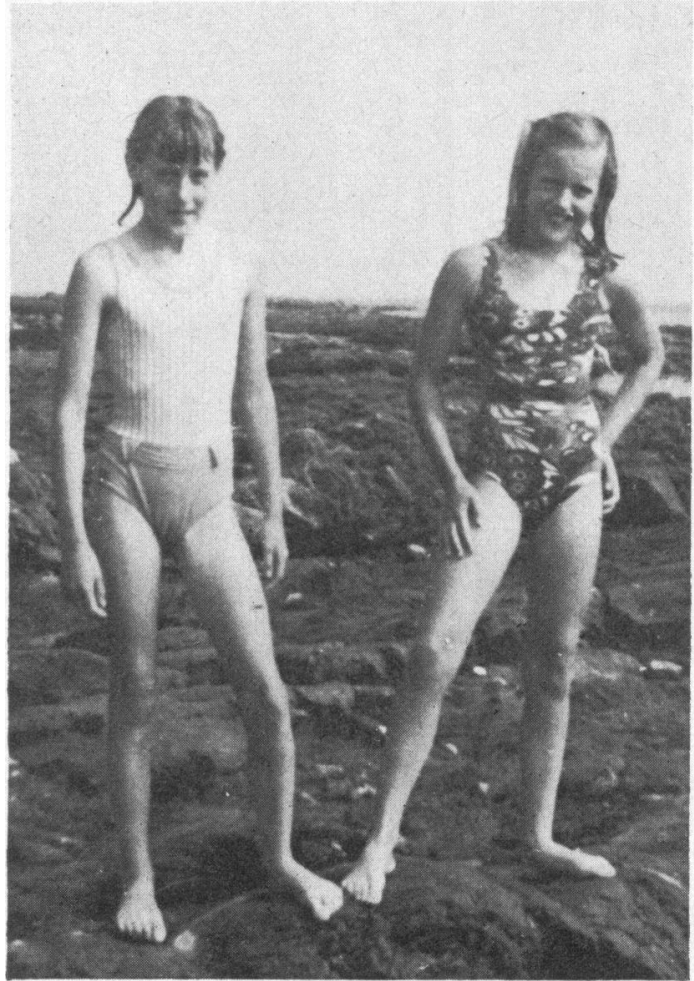

FIG. 3.-Appearance of the twins at age 10 years. Twin $B$ is on the left as in Fig. 1. 
In contrast to twin $A$, twin $B$ was paler, with somewhat stooping posture and showed a slightly pinched facies and mouth breathing. A marked expiratory wheeze and scattered rales were audible on auscultation of the chest. Physical examination otherwise was normal and she too showed left cerebral dominance.

The results of intelligence and educational attainment testing for the twins in June 1973 (aged 10 years 1 month) are shown in Table IV.

TABLE IV

Intelligence and educational attainment testing at 10 years of age

\begin{tabular}{l|c|c}
\hline & Twin A & Twin B \\
\hline WISC & 104 & 106 \\
Full scale IQ & 108 & 108 \\
Verbal scale IQ & 100 & 103 \\
Performance scale IQ & 108 & 111 \\
WRAT & 106 & 103 \\
Reading & 96 & 103 \\
Spelling & & \\
Arithmetic & & \\
\hline
\end{tabular}

WISC, Wechsler Intelligence Scale for Children;

WRAT, wide range achievement test.

Both twins were of average intellectual ability and school performance was considered to be identical. However, the parents considered that twin B was more persistent and determined and neater with writing than her sister, but emotionally was the more temperamental.

\section{Discussion}

These twins, on the basis of the type of placenta, identical blood grouping, and subsequent physical characteristics, are clearly monozygous. They are of particular interest in that having been born with extreme differences in weight and length they have subsequently shown remarkable similarity in physical and intellectual development. The difference in weight at the age of 10 years could be attributed to the asthmatic bronchitis of the smaller twin (which was not well controlled) rather than to the difference in birthweights.

In terms of gestational age both twins should be considered mature. Yet, at birth, twin B was not only much lighter in weight, but also less in length and skull circumference and retarded in bony development. This suggests that the adverse prenatal factors responsible had been operating for a considerable time. The features of the smaller twin illustrate that many of the frequently accepted criteria for assessing maturity may be misleading. Scott and Usher (1964) have shown that epiphyseal development may be markedly delayed in utero when the fetus is malnourished, and the state of the epiphyses correlates better with birthweight (or even body length) than with gestational age.

It seems reasonable to assume that the slow intrauterine growth of the smaller twin was due to inadequate fetal nutrition that was presumably due to placental insufficiency. It is possible that these twins represent the outcome of the 'placental transfusion' syndrome. Strong and Corney (1967), in reviewing many reports, have shown that in the majority of monochorionic placentas there are vascular anastomoses (as shown in this case). Twins with such placentas may show a marked difference in $\mathrm{Hb}$ levels. The anastomoses presumably act as uncompensated shunts from one half to the other, and the consequent transfusion may result in death of one fetus or, if both survive, great disparity in their weights. However, the difference in $\mathrm{Hb}$ levels in these twins was only $40 \%$, which is much less than would have been expected if this was the major aetiological factor. There was, in addition, definite damage to one-half of the placenta. The threatened abortion that occurred early in the pregnancy could have been due to partial separation of one-half of the placenta, which subsequently became inadequately vascularized (as indicated by the ultimate appearances macroscopically, histologically, and radiologically).

It is generally considered that babies of very low birthweight due to intrauterine malnutrition suffer long-term consequences in growth (Babson, 1970; Fitzhardinge and Steven, 1972a; Cruise, 1973) and in intelligence and emotional development (Neligan, 1971; Fitzhardinge and Steven, 1972b). This is most striking in those babies like twin B weighing less than $1360 \mathrm{~g}$ (McDonald, 1967). This is well illustrated by studies on twins, which provide a good control series, and there are many reports which show that the smaller of twins persists in being behind in physical growth and intelligence (Babson et al., 1964; Babson and Phillips, 1973; Churchill, 1965; Hohenauer, 1971). This is particularly apparent with monozygous twins with a great difference in birthweight. Kaelber and Pugh (1969) studied 374 sets of twins and did not find a statistical difference on IQ testing (at ages between 6 and 16 years) with dizygous twins of like sex or monozygous twins whose birthweights differed by less than $300 \mathrm{~g}$. However, monozygous twins with a greater difference in birthweight than this showed a mean IQ difference of $5 \cdot 76$, which was highly significant statistically. Fuller analysis of previous reports of other authors confirmed this conclusion.

The twins reported here should in all these respects be expected to differ in physical and intellectual attainment. The difference in birth- 
weight of $1640 \mathrm{~g}$ is among the greatest recorded and yet the twins have developed in a remarkably similar fashion, with no significant difference in intelligence. The birthweight difference was $55 \%$, greater than any of the 9 pairs of monozygous twins recently reported by Babson and Phillips (1973). In all those twin pairs the twin which was smaller at birth persisted in being smaller in height, weight, and head circumference and of inferior intelligence when re-examined at mean ages of 8 and 13 years. Babson and Phillips have suggested that the reduced intelligence found in the smaller of twin pairs is due to impaired nutrition to the brain at a critical period of its development. The period of fetal undernutrition in the smaller twin reported here was at a time of rapid brain growth, and her head circumference was smaller both at birth and at school age, yet her intelligence has not been impaired. Catch-up growth of this smaller twin was very rapid after birth, and this may indicate that satisfactory postnatal nutrition can sometimes compensate for the adverse effects of intrauterine malnutrition in determining the ultimate physical and mental outcome.

We thank Sir Charles Harris ${ }^{\star}$ for permission to report these twins; and Dr. G. S. Udall and Mr. J. E. Drinkwater for undertaking developmental assessment.

$\star$ Now deceased.

\section{REFERENCES}

Babson, S. G. (1970). Growth of low-birth-weight infants. fournal of Pediatrics, 77, 11.

Babson, S. G., Kangas, J., Young, N., and Bramhall, J. L. (1964). Growth and development of twins of dissimilar size at birth. Pediatrics, 33, 327.

Babson, S. G., and Phillips, D. S. (1973). Growth and development of twins dissimilar in size at birth. New England fournal of Medicine, 289, 937.

Churchill, J. A. (1965). The relationship between intelligence and birth weight in twins. Neurology, 15, 341.

Cruise, M. O. (1973). A longitudinal study of the growth of low birth weight infants. I. Velocity and distance growth, birth to 3 years. Pediatrics, 51, 620.

Fitzhardinge, P. M., and Steven, E. M. (1972a). The small-for-date infant. I. Later growth patterns. Pediatrics, 49, 671 .

Fitzhardinge, P. M., and Steven, E. M. (1972b). The small-fordate infant. II. Neurological and intellectual sequelae. Pediatrics, 50, 50.

Hohenauer, L. (1971). Prenatal nutrition and subsequent development. Lancet, 1, 644.

Kaelber, C. T., and Pugh, T. F. (1969). Influence of intrauterine relations on the intelligence of twins. New England fournal of Medicine, 280, 1030.

McDonald, A. (1967). Children of Very Low Birth Weight. Spastics Society and Heinemann, London.

Neligan, G. A. (1971). The effects of intrauterine malnutrition upon later development in humans. Psychiatria, Neurologia, Neurochirurgia, 74, 453.

Scott, K. E., and Usher, R. (1964). Epiphyseal development in fetal malnutrition syndrome. New England fournal of Medicine, 270, 822.

Strong, S. J., and Corney, G. (1967). The Placenta in Twin Pregnancy, p. 65. Pergamon Press, Oxford and London.

Correspondence to Dr. J. M. H. Buckler, Department of Paediatrics and Child Health, University of Leeds, 27 Blundell Street, Leeds LS1 3ET. 
Rolfe, P. (1971). A magnetometer respiration monitor for use with premature babies. Biomedical Engineering, 6, 402.

Rolfe, P. (1972). The use of magnetometer respiration monitor with premature infants. Proceedings of the Biomedical Engineering Congress, Session 2, Milan.

Scopes, J. W. (1971). Respiratory distress syndrome. In Recent Advances in Paediatrics, 4th ed., p. 81. Ed. by D. Hull and D. M. T. Gairdner. Churchill, Edinburgh and London.
Veasey, L. G., Clark, J. S., Jung, A. L., and Jenkins, J. L. (1971). A system for computerized automated blood gas analysis. Its use in newborn infants with respiratory distress. Pediatrics, 48, 5.

Correspondence to Dr. N. R. C. Roberton, Department of Paediatrics, John Radcliffe Hospital, Headington, Oxford OX3 9DU.

\section{Corrigendum}

On page 473 of the June issue in 'Matched development of a pair of monozygous twins of grossly different size at birth' by J. M. H. Buckler and A. Robinson, Archives, 1974, 49, 472, under 'Initial progress', the second paragraph should read:

'Over the course of the first year, the smaller twin caught up her larger sister rapidly. At 14 weeks the weights of twins A and B were $5 \cdot 78$ and $4.54 \mathrm{~kg}$, and at $11 \frac{1}{2}$ months 7.94 and $7 \cdot 63 \mathrm{~kg}$, respectively.' 